NBER WORKING PAPER SERIES

LABOR DEMAND AND THE STRUCTURE OF ADJUSTMENT COSTS

Daniel S. Hamermesh

Working Paper No. 2572

NATIONAL BUREAU OF ECONOMIC RESEARCH

1050 Massachusetts Avenue

Cambridge, MA 02138

May 1988

Professor of economics, Michigan State University, research associate, National

Bureau of Economic Research. I thank John Goddeeris, Bob Gregory, Steve Martin, Kevin Murphy, Sherwin Rosen and participants in seminars at the National Bureau of Economic Research and several universities in the United States and Australia for helpful comments. I owe a special debt to the staff of the company who took the trouble to provide the data underlying the estimation in Section $V$. The research reported here is part of the NBER's research program in Labor Studies. Any opinions expressed are those of the author and not those of the National Bureau of Economic Research. 
NBER Working Paper \#2572

May 1988

\section{LABOR DEMAND AND THE STRUCTURE OF ADJUSTMENT COSTS}

\section{ABSTRACT}

This study examines the nature of the costs that firms face in adjusting labor demand in response to shocks induced by changes in output demand and prices. Empirical work on monthly plant-level time-series data shows that adjustment proceeds in jumps: Employment is unchanged in response to small demand shocks, but moves instantaneously to a new long-run equilibrium if the shocks are large. Results in the large literature that assumes smooth adjustment are due to aggregation of this inherently nonlinear relation over subunits experiencing different shocks. The finding has implications for cyclical changes in productivity and for examining the effects of policies such as severance pay, layoff and plant-closing restrictions, and mandatory listing of job vacancies, all of which change the cost of adjusting employment.

Daniel S. Hamermesh

Department of Economics

Michigan State University

East Lansing, MI 48824 


\section{Introduction}

Most models of factor adjustment assume smooth paths from an initial to a final equilibrium when the fundamental determinants of factor demand are shocked. Indeed, most recent econometric work has even assumed that the adjustment is characterized by a geometric lag structure. The purposes of this study are to reexamine the theory underlying these assumptions, to discover whether they make sense empirically, and to consider the implications of alternative estimates that allow one to infer the structure of the costs of adjusting labor demand.

This reexamination is necessary for several reasons. It may be that predictions of the paths of factor demand are unaffected by econometric specifications that fail to embody the underlying structure of the adjustment costs that face decision-makers at the firm level. However, without specifying and estimating equations that embody these structures we cannot know if this is so. Secondly, in most European countries, and increasingly in the United States too, a variety of labor-market policies has been enacted in the past 15 years that can be characterized as affecting the adjustment of labor demand: Without knowing more about the structure of adjustment costs, we cannot link specific policies to those costs in order to infer how the policies affect the labor market.

I begin by examining the origins of the conventional wisdom about factor adjustment, including issues of aggregation. The section also discusses the nature of labor costs and distinguishes between static costs and those associated with altering employment. Next I analyze the optimal path of employment under generalized costs of adjustment. The inferences about the adjustment paths are used to specify a set of estimating equations. These are studied using data on individual plants and then on longer time series on highly disaggregated industries. The empirical analysis provides the first 
tests of conpeting hypotheses about the structure of the costs of adjusting labor demand, and it does so using the appropriate micro data.

\section{The Conventional Hisdom, Suggested Emendations and the Nature of Labor Costs}

The conventional model of dynamic factor demand specifies an equation system such as:

(1) $X_{i, s}=F\left(X_{1, t-1}, \ldots, X_{i, t-k}, \ldots, X_{M, t-K}, Z_{i t}, \ldots, Z_{j, t-1}, \ldots, Z_{\mathrm{W}, t-L}\right)$;

$$
i=1, \ldots, M ; k=1, \ldots, K ; j=1, \ldots, N ; I=1, \ldots, L,
$$

where $t$ denotes tire, the $x_{i}$ are inputs and the $z_{j}$ are exogenous variables. In early studies and the recent studies that have concentrated on how expectations affect the structure of the variables in $Z, M=x=1 \ldots i$.e., a simple geometric lag structure is imposed and the adjustment of and demand for the single input of interest is assumed to be independent of the adjustment and demand for other inputs. Thus Rosen (1968) examines the adjustment of the employment-hours ratio with $M=K=1$. Sargent (1978) studies the dynamics of Iabor demand with $M=1$ but with a very complex lag structure on the $\mathrm{X}_{\mathrm{t}-\mathrm{x}}$ for labor. In the estimation of large macroeconomic models the assumption that $K=1$ has become standard (see, e.g., Fair, 1984).

A variety of other studies has examined (1) with $M>I$ under varying degrees of generality about the lags of the inputs other than $X_{1}$ included in each equation and about the $Z_{j}$. Thus Hamermesh (1969) examined gross employment changes in this context; Brechling (1975) and Shapiro (1986) studied simultaneous employment and capital-stock adjustment; Topel (1982) specified inventories and employment as adjusting together; and Nadiri-Rosen (1969) included all of these decision variables in a model like (1).

All of these studies specify factor adjustment as a simple distributed $\mathrm{lag}$, with initial partial adjustment of the $\mathrm{X}_{1}$ in response to changes in 
the $z_{j}$. In most, equilibrium is approached only asymptotically because a geometric $\operatorname{lag}$ structure is imposed. Its imposition is justified by arguing that the costs of adjustment are convex. Apparently the first use of this assumption was by Holt et al. (1960). Yet in discussing decision rules about labor use, those authors noted, "Whether these costs [of changes of various sizes in the work forcel actually rise at an increasing or decreasing rate is difficult to determine. [p. 53] Indeed, they draw an adjustment cost function without fixed costs and with linear variable costs. They justify a convex (quadratic) curve as an approximation that allows the derivation of linear decision rules for adjusting inputs.

Subsequent theoretical work derived explicit paths for factor demand under the assumption of quadratic variable adjustment costs and no fixed costs of adjustment: Yet none of the leading studies (Eisner-Strotz, 1963; Gould, 1968) provides much more justification for the assumption than do Holt et al. More recent work just imposes the assumption of quadratic variable and zero fixed adjustment costs with no discussion of why this representation of the structure may be correct (e.g., Sargent, 1978, p. 1016). Indeed, the assumption that this particular structure characterizes the world has found its way down to intermediate macroecononics texts (Froyen, 1983, p. 353). Obviously there is nothing wrong a priori with the assumption, However, its exclusion of fixed costs and its insistence on increasing average variable adjustment costs are very restrictive and not necessarily consonant with reality.

In the literature on labor demand only Nickell (1986, and some of his earlier work) recognizes that increases or decreases in employment may be characterized by average variable costs of adjustment that are initially decreasing but eventually increasing. He derives the firm's dynamic demand for labor under both the standard assumption of increasing variable costs and the assumption of constant costs. There is no existing empirical work on 
labor demand, however, that goes beyond the conventional assumptions. ${ }^{2}$

Trivedi (1985) shows that there are severe difficulties jn drawing inferences about microecononic adjustment paths from aggregated data. This suggests that empirical work on the adjustment of labor demand should first examine microconomic adjustwent paths to fnfer the nature of those coste. It should then consider how these micro paths are aggregatod to produce the more readily observabie macro paths. ${ }^{3}$ The firet step reguires a discuseion of the nature of these costs at the micro levej.

One must be very carefin to distinguth fred and variable adjutante costs from fired and variable static costs. There 15 no necosary relationship betwen the relative sizes of adustment costs and gatho costanong

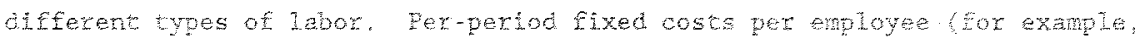
heal th insurace premiuns) may be relatively Iarge for a grow of (presuraty low-skilied) workers for whon fixed (one-tine thring and fin-specific training costs are small. Conversely and obversely, the relative cost of an

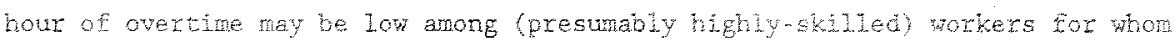
the warghal cost of hing and tratning th hith

The most casual experience wh hing huggests that much of the cost engendered is independent of the nuber of workers bired. Advertisinf. interviewing anc doing the paper work necesary to the one assistant professon of economics is no more costly than that required to hire three. Taking experienced workers away from production to train one worket may be as costly as taking then away to train five workers. This is not simply a matter of economies of scale in the size of the adjustment: There are some costs that arise only if an adjustment is made and that do not vary with the size of the adjustment.

In adifion to the uniknown structure of these costs of gross changes in employment, there are also costs of net employment changes whose structure is 
unknown to the observor. Does reducing employment by eliminating a shift reduce profits proportionately more or less than a reduction in employment that occurs when a few workers are laid off? Do morale problems arise among the remaining workers when staffing is reduced regardless of the size of the reduction? These questions suggest that the structure of the costs of adjusting employment levels need not be convex and may affect the path of employment just as much as the more visible costs of gross employment changes.

Even the level of variable relative to fixed adjustment costs is difficult to discern from the sparse published data. The typologies by which hiring and separation costs are categorized in the (very few) available surveys of employers ... such as advertising, training, etc. ... do not allow for an easy link to the economic concepts outlined here." These surveys tell us nothing about adjustment costs that arise when production is disrupted by changes in staffing. The study of the structure of the costs of changing flows and stocks of employment is barely in its infancy.

\section{Adjustment Paths}

To analyze the adjustment of labor demand in response to exogenous shocks, let us simplify by assuming that the product price is unchanged for ali time at $P=1$, and that the employer knows that the wage, which changes at time zero, will be constant thereafter. (We could equally well hold the wage fixed and assume a price shock.): I write the concentrated production function as $Q=F(L)$, where $L$ is the labor input. ( $I$ ignore the issue of employment-hours substitution and assume in this derivation that hours per worker are fixed. See Hart, 1984.). The firm's static profit function is $\pi(\mathrm{L})$, with $\pi^{\prime}>0, \pi^{\prime \prime}<0$, and $\pi^{\prime}\left(L^{*}\right)=0$, where $L^{*}$ is the long-run profitmaximizing labor demand.

Without loss of generality I assume that the variable costs of 
adjusting labor demand are quadratic in the size of the adjustment. The fixed costs of adjusting labor demand are $k>0$. Both fixed and variable costs are symetric in the direction of the adjustment, a simplifying assumption that does not qualitatively change the results. The adjustment cost function is then:

$$
C(\dot{L})=b \dot{L}^{2}+\left\{\begin{array}{l}
\mathrm{K} \text { if }|\dot{L}|>0 \\
0 \text { if } \dot{L}=0
\end{array}\right.
$$

where the superior dot denotes the rate of charge, and $b$ is a paranecer of the adjustment cost function. (I exclude a Inver tem in $i$; were it inciuded, ths only effect on the path would be to change the target.) Implicitly this cost structure is on net changes in erployent, an approach taken in some but not all of the interature.

To simplify the analysis of the firm's optrit path, solve fto problen by characterizing its discounted stream of profits as:

(2) $z=\int_{0}^{\pi}\left[\pi(L)-b L^{2}-k\right] e^{-r t} d t+\frac{\pi\left(L_{I}\right) e^{-\tau T}}{I}$, where $0 \leq \tau \leq \infty$ is the point when the firm stogs adyuting its labor denad in response to the shock that occurred at $t=0$, the that rate is impirit In the function $\pi$, and $\mathrm{L}_{\mathrm{T}}$ is the value of $\mathrm{L}_{\text {that }}$ th chosen at the endogenous time $T$. The fim wishes to maximize (2) subject to the intial condition $L(0)=L_{0}$ and under the arbitraty assuption that $i \geq L_{0}^{*}$ (that $i s$, was decreased.$^{5}$

If $\mathrm{b}>0$ and $\mathrm{k}-0$, the optimal adjustment path between $t=0$ and $I$ is described by the Euler equation:

3) $2 \mathrm{~b} \dot{L}^{\prime \prime}-2 \mathrm{br} \dot{L}+\pi^{\prime}(\mathrm{L})=0 ; L(0)=L_{0}, L(T)=L_{T}$.

This is the standard solution, with $T+\infty$ and $L_{T} \rightarrow I^{*}$. The adjustment path is smooth, and the equilibrium labor demand is approached asymptotically. 
Obversely, if $b=0$ and $k>0$, the firm sets $T=0$ and $\operatorname{sets} L_{T}=L_{a}$ or $L_{T}=L^{*}$ depending on whether:

$$
k \geq \frac{\left[\pi\left(L^{*}\right)-\pi\left(L_{0}\right)\right]}{r} .
$$

In the general case $b, k>0$. The nature of the solution depends on the relative sizes of these two parameters, the discount rate $r$, and the structure of the profit function $\pi$. Two additional equations beyond (3) describe the solution completely in this case. The first is:

(4) $\quad-2 b \dot{L}_{\mathrm{T}}+\frac{\pi^{\prime}\left(\mathrm{L}_{\mathrm{T}}\right)}{\mathrm{r}}=0$.

The economic interpretation of (4) is that the present value of the marginal profits from increasing $L_{T}$ must equal the marginal adjustment costs of that increase. The second additional condition is:

(5) $\quad-b \dot{L}_{T}^{2}+\frac{\pi^{\prime}\left(L_{T}\right) \dot{L}_{T}}{r}-k=0$.

This condition states that the present value of the increased profits from raising $T$ must equal the increased cost of adjustment.

Together (3)-(5) imply an adjustment path in which, if the shock is relatively small, the firm does not adjust its labor demand. If the shock is large enough, though, labor demand will adjust smoothly toward $L^{*}$; but the firm will stop changing its labor input before $L^{*}$ is reached. The comparative dynamics of the system can be analyzed to show the effects of changes in the underlying parameters on this path.

Equation ( 5 ) is a quadratic in $\dot{L}_{\mathrm{I}}$. It has real roots only if:

$$
\left|\frac{\pi^{\prime}\left(L_{T}^{2}\right)}{r}\right|^{2} \geq 4 \mathrm{bk} .
$$

Since we know that $\pi^{\prime}\left(L^{*}\right)=0$, and since both $b$ and $k$ are positive in general, this condition means that in general $\mathrm{L}_{\mathrm{T}}<\mathrm{L}^{*}$. We can rewrite this condition and substitute in (4) to obtain:

(4') $\quad L_{I} \geq\left|\frac{k}{b}\right|^{1 / 2}$

and 


$$
\pi^{\prime}\left(L_{T}\right) \geq 2 r[b k]^{1 / 2} \text {. }
$$

Equation $\left(5^{\prime}\right)$ shows that as $k$ increases the slope of the profit function at the teminal point increases; equation (4') shows that an increase in $k$ raises the rate of adjustment at the teminal point. Together these inferences show that higher fixed costs of adjustnent increase the, gap between $I_{T}$ and $L^{*}$ and reduce $T$. An increase in $b$ increases the slope of the profit function at the teminal point, but it reduces the rate of adjustmenc at $T$. Together these facts imply that increased $\mathrm{b}$ rajses the gap between $L_{I}$ and $L^{*}$, but that it takes longer for the finh to ajust from $I_{0}$ to $L_{T}$. Finally, increased $r$ reduces $\mathrm{L}_{\mathrm{T}}$.

This discussion of adjustment paths sugggests there is little justification except simplicity for assuming away fixed costs and positing that the variable costs facing the firm are quadratic. As we have seen, avoiding this simplification changes and enriches the predictions about paths of adjustment of labor demand in response to external shocks. The task of the empirical work here is to add the complexities -- the possibilities of discrete jumps in cemand and of incomplete adjustment ... and test whether they explain adjustment paths of employment at the micro level better than do the standard models of smooth adjustment. The second step required to understand factor adjustment at the macro level -.. the analysis of the appropriate aggregators of the micro paths produced by the adjustment cost structures facing each firm -. is left to subsequent research.

\section{Implications for Estimation}

The standard estimating equation equation corresponding to (1) can in the simplest case be written as:

$$
L_{t}=[1-\gamma] L_{t-1}^{\star}+\gamma L_{t-2}+\mu_{t}
$$

where $L$ and $L^{*}$ are the logarithms of actual and long-run (static) equilibrium labor demand respectively, $t$ denotes time, and $\mu$ is a random error term 
(whose distribution I leave temporarily general). This equation is based on the usual assumption of convex variable adjustment costs with no fixed adjustment costs.

If those variable costs are not convex, or if there are fixed costs of adjustment, Section III showed that the long-run profit-maximizing firm will either not adjust or will immediately set $L=L^{*}$. I have shown that the second choice will be made if the long-run static $L^{*}$ is sufficiently different from the most recent choice of $\mathrm{L}$ and if $\mathrm{k}$ is relatively small. We can make this operational by describing the firm's choices about employment in the plant by: (7a) $L_{t}=L_{t-1}+\mu_{1 t} \cdot\left|L_{t-1}-L_{t}^{*}\right| \leq K$ and (7b) $\mathrm{L}_{\mathrm{t}}=\mathrm{L}_{\mathrm{t}}^{*}+\mu_{2 \mathrm{t}^{*}} \quad\left|\mathrm{~L}_{\mathrm{t}-1}-\mathrm{L}_{\mathrm{t}}^{*}\right|>\mathrm{K}$, where $K$ is a parameter that is an increasing function of the fixed adjustment costs facing the firm. $K$ is the percentage deviation of last period's employment from desired employment that is necessary to overcome the fixed costs of adjusting the amount of labor used. I assume that $E\left(\mu_{1 t} \mu_{2 t}\right)=0$. To estimate (7) we need to specify $L_{t}^{*}$... Let:

(8) $L_{t}^{*}=a X_{t}+\epsilon_{t}$ where a is a vector of parameters, $X$ is a vector of variables that affect $\mathrm{L}_{\tau^{x}}^{*}$ and $\epsilon_{\mathrm{t}}$ is a disturbance term. (I assume that $E\left(\mu_{1 t^{t}} \epsilon_{t}\right)=E\left(\mu_{2 t_{\mathrm{t}}} \epsilon_{\mathrm{t}}\right)=0$ throughout the discussion.) The firm operates on (7a) if:

$$
\epsilon_{\mathrm{t}} \leq \mathrm{K}+\left[\mathrm{L}_{\mathrm{t}-1}-\mathrm{aX}_{\mathrm{t}}\right] \text { and } \epsilon_{\mathrm{t}} \geq-\mathrm{K}+\left[\mathrm{L}_{\mathrm{t}-1}-\mathrm{aX}_{\mathrm{t}}\right] .
$$

It operates on (7b) if:

$$
\epsilon_{t}>K+\left[L_{t-1}-a X_{t}\right] \text { or } \epsilon_{t}<-K+\left[L_{t-1}-a X_{t}\right]
$$


It jumps to its new long-run equilibrium (moves along (7b)) if it is sufficently shocked by changes in $X$ or if it makes errors in forecasting $L_{t}^{*}$ that are not captured in the variables we use in the vector $X$.

We need to specify $L^{*}$ and to construct a method of estimating the parameters in (7) ... the a parameters and the variances $\sigma_{\mu_{1}}^{2}, \sigma_{\mu_{2}}^{2}$ and $\sigma_{\epsilon}^{2}$.

The system (7a) and (7b) is essentially a switching regression (see GoldfeldQuandt, 1976), with the probability of being on (7a) equal to:

$$
1-P_{t}=\Phi\left[\frac{K+L_{t-1}-a X_{t}}{\sigma_{t}}\right]-\Phi\left[\frac{K+L_{t-1}-a X_{t}}{\sigma_{\epsilon}}\right] \text {. }
$$

where 1 is the cumulative unit normal distribution function (and I have implicitly assumed that $\epsilon$ is nomally distributed). $\mathrm{P}_{t}$ is then the probability that the firm jumps to $\mathrm{L}_{\mathrm{t}}^{*}$. The likelihood function characterizing the switching model is:

(9) $\quad f=\prod_{t=1}^{T} \mathcal{E}\left(\mu_{1 t}\right)^{1-p_{t}} \cdot g\left(\mu_{2 t}+\epsilon_{t}\right)^{P_{t}}$, where $g\left(\mu_{1 t}\right)$ is the density of $\mu_{1 t}$ from $(7 a)$, and $g\left(\mu_{2 t}+\epsilon_{t}\right)$ is the density of the error term in (7b), after substituting for $L_{t}^{*}$. Both errots are assuned to be distributed normally. The logarithm of the likelihood function in (9) is maximized in the empirical work in the next two sections.

A huge literature has arisen or the appropriate specification of $L^{*}$ (see Hamemesh, 1986a). Since my purpose here is not the estimation of static labor-demand relations, and since the available data limit the possibilities severely, I use two different approaches to estimate $L_{t}^{*}$ for use in (6) and (7). The first, which can be viewed as perfect forecasting under rational expectations, simply lets:

(10) $L_{t}^{*}=a_{0}+a_{2} Y_{t}+a_{3} t+\epsilon_{t}$. 
where the $a_{i}$ are parameters to be estimated. ${ }^{\sigma}$. The second, based on a simplified version of Nickel1's (1984) approach, estimates a transfer function for $Y_{t}$ using all information available at time $t-1$. This produces the prediction ${ }_{t-1} \mathrm{Y}_{\mathrm{t}}^{*}$ as well as allowing predictions of $\mathrm{Y}_{\mathrm{t}+1}^{*}, 1-1,2, \ldots$ In this approach $L_{t}$ is approximated as:

(11) $L_{t}^{*}=a_{0}+a_{1 t-1} Y_{t}^{*}+a_{2} \Delta Y_{t+1}^{*}+a_{3} t+\epsilon_{t}$ where $\Delta \mathrm{Y}_{t+1}^{*}$ is the change in the forecasted value $\mathrm{Y}^{*}$ from time $t$ to time $t+i$. This simple equation reflects the role of labor-saving technical change and expectations about sales. ${ }^{7}$

If the behavior characterizing individual firms is described by (7), and firms differ in the sizes of their $\left|L_{t-1}-L_{t}^{*}\right|$ and their $K$, at any time $t$ some fraction $\delta_{\varepsilon}$ of the firms in any aggregate will hold employment constant at $L_{t-1}$ (will behave according to $(7 a)$ ), while $1-\delta_{t}$ of the firms will adjust according to (7b). If we observe only the behavior of the aggregate, we will find that the adjustment of labor demand will be characterized by an equation that looks just like ( 6 ) (with $\delta$ substituted for $\gamma$ ). If one ignores the timevarying nature of the $p_{t}$ and the problems of aggregating individual firms' $p_{t}$ co obtain $1-\delta_{t}$, the standard specification in $(6)$ describes aggregate employment dynamics fairly well even though the underlying behavior is characterized by (7)

Equation (6) is based on quadratic variable adjustment costs, so that $y$ is presumably related to the quadraticity of the adjustment cost function: Estimates of $\gamma$ could be related to the characteristics of firms that make them adjust slowly or rapidly in response to shocks. Equations (7) are based on fixed adjustment costs. Estimates of $k$ could be used to indicate which firms change employment in response to small demand shocks and which firms have sufficiently large fixed costs of adjustment that they change employment 
only in response to large shocks. In the presence of aggregation it is difficult to distinguish between these two possibie adjustment cost structures, and between these two quite different views of the nature of firms responses to shocks to factor demand.

7. Fstimatos for Individual Plants

To examine the effects of differing structures of adjustment costs at the proper level of disaggregation I acquired data on seven manufacturing planes of a laxge U.S. corporation. Monthly data on output were obtained for December 1977 through May 1987 , as were monthly enploynent levels from jamary 1983 through May 1987. In addition to estimates over the individual plants for February 1983 through May 1987, I also present estimates based on the aggregations of employment and output over ali seven plants; and on the pooled sample of 364 observations.

The employment data are mid-month counts of production. workers in each plant. The output data measure total production in the month. During the 53 months for which I have employment data there were no major strikes in this company. A few plants were shut down due to strikes for less than one week, but this does not seem to have affected production worker employment or monthly totals on output.

Before proceeding to the estimation of (7), a detalled preview of the results can be obtained by examining plots of the logarithms of employment and output in the seven plants, and of the aggregated data covering these plants. The data are presented ir Figure I. Each plot shows the 52 months of the sample period; each origin represents February 1983 and the minimurn value of the logartthm of one plus the plant's employment level. The first seven plots are striking. There are substantial fluctuations in output; but production-worker employment is essentially constant, except for large changes about the time of the larger changes in output. This is seen especially 

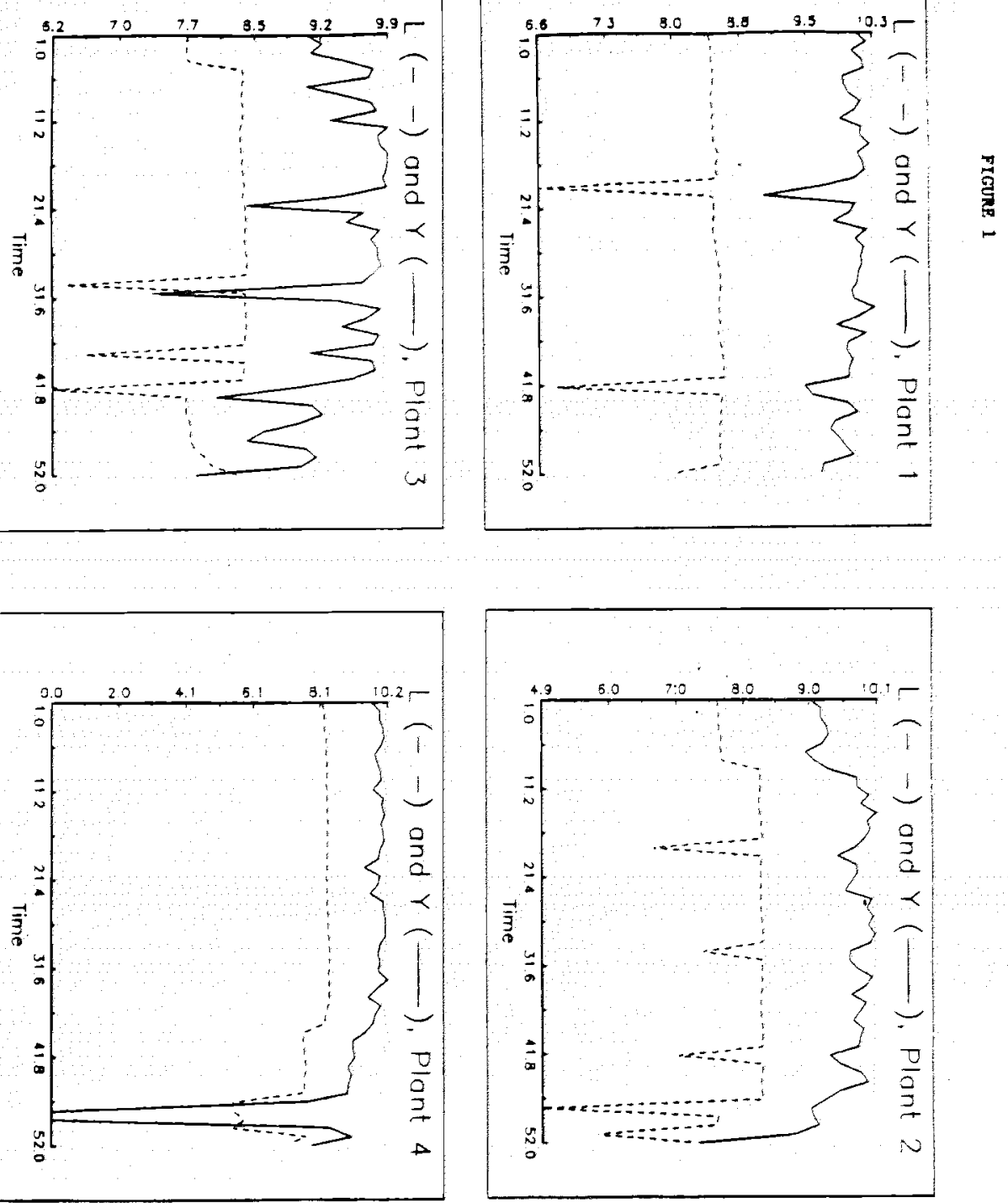

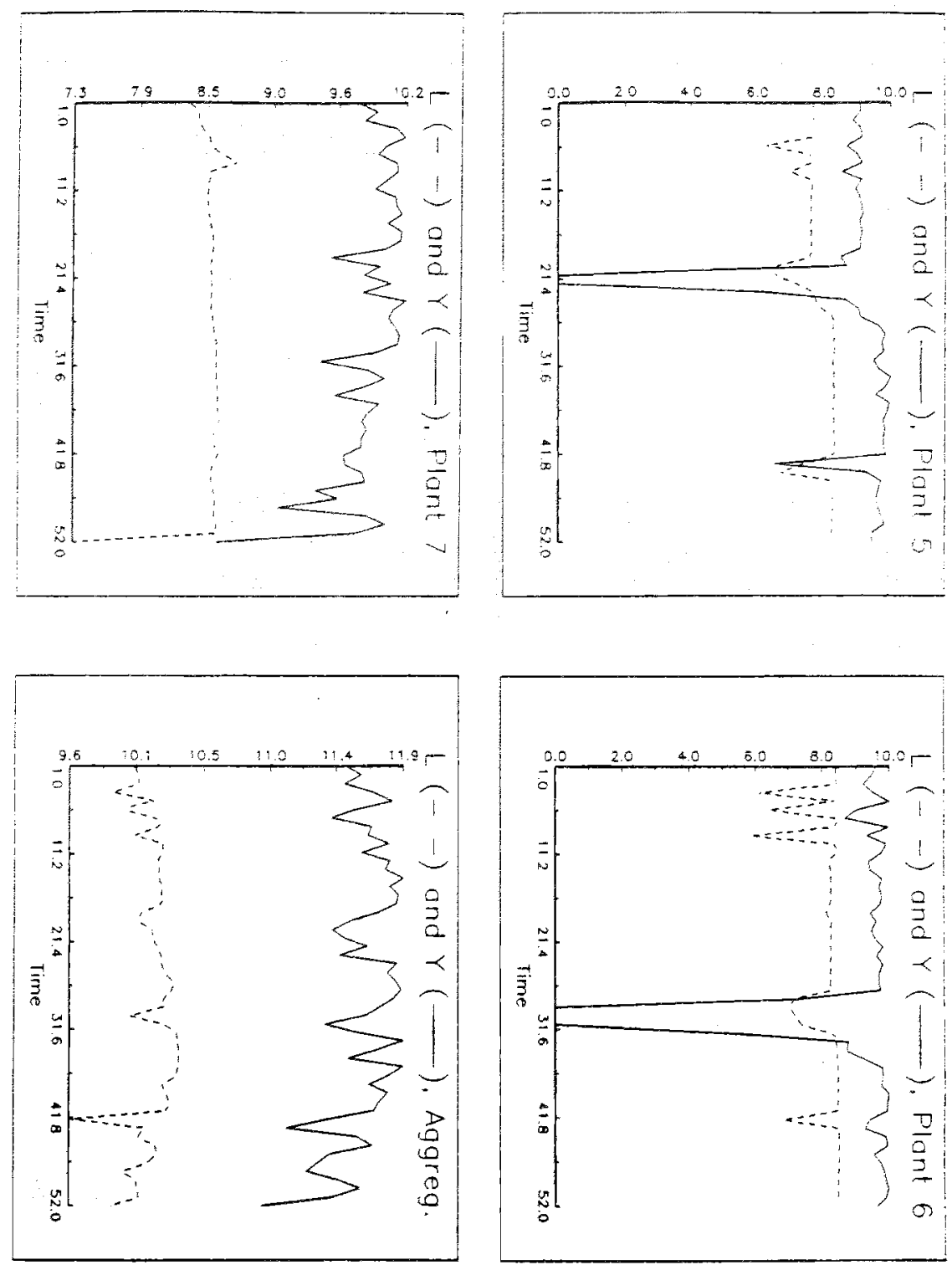
clearly in the data for Plants 1,4 and 5, but appears to characterize the data for the other four plants too. This inference contrasts sharply with the appearance of the data aggregated over the seven plants, shown in the last plot. There are continuous fluctuations in employment, and these roughly coincide with the fluctuations in output. The first seven plots are quite inconsistent with a model of smooth fluctuations in employment based on convex variable adjustment costs; the last plot appears consistent with such a model. While these figures tell much of the story, they cannot tell us whether the underlying relationship between the logarithms of employment and output ( $L$ and $Y$ ) are consistent with the static theory of production; nor can they provide us with insights into the size of the shock, $K$, that is necessary to induce the firm to change employment in the plant. To make these inferences we must estimate (7) and the accompanying equation, alternatives (10) or (11). Throughout the analysis I use seasonally unadjusted data: Only in Plant 3 was there significant twelfth-order autocorrelation in $Y$.

To generate the sequences $t-1 \mathrm{Y}_{t}^{*}$, I initially used a transfer function based on continuously-updated regressions of $Y$ on its 12 lagged values, a time trend, and the 12 lagged values of the company's retail sales. While these regressions fitted better than did those that excluded the firm's retail sales, they did not predict $Y$ so well. Accordingly, (7) is estimated using ARI(12) forecasts of $Y$. Each forecast is based on the most recent five years of data on output.

A comparison of the estimates of (6) and (7) is essentially a test of how the standard model of convex variable costs of adjustment performs relative to a model in which variable costs are of degree one or less, but there are fixed adjustment costs. Under alternative (10) the model in (6) has five parameters $\ldots$ the four regression parameters $a_{0}, a_{1}, a_{3}$ and $\gamma$, and $\sigma_{\mu}$. 
Under the same alternative the switching model has seven parameters -. the three $a_{1}, K, \sigma_{\epsilon}, \sigma_{\mu_{1}}$, and $\sigma_{\mu_{2}}{ }^{2}$ To make estimation of the system somewhat easier, I assume that $\sigma_{\mu_{i}}=\sigma_{\mu_{2}}$. This means that I an restricting the variance of the error in (7a) to be less than that in (7b). This implicitly assumes that errors that occur when the firm seeks to hold employment constant are not likely to be so large as those produced when the firm tries to move from $L_{t-1}$ to $\mathrm{L}_{t}^{*}$. The basic switching model thus has stw tree parameters. While (6) is not nested in (7), wo can discrininate between them by examining the values of the likel thood functions of each.

I begin with a discussion of the estimates of an autoregression of $L$, and of (11) and two alternatives of $(6)$, which are shown in Table $1 .{ }^{3}$ The estimates for the individual plants are not too encouraging, as they contain some negative autoregressive terms in the $A R(1)$ model and in (6), some positive time trends and even a negative coefficient on expected output for plant 1. This instability across the plants is probably tue to the use of microeconomic data and to the relatively few observations avaliable for each plant.

The estimation problems induced by this combination are overcome when either the pooled or the aggregated data underlie the estimation. The results for these two cuts of the data are shown. In the first two tableaux of Table 1 . In the aggregated data the coefficients on ${ }_{t-1} Y_{t}^{*}$ are consistent with previous work using industry data; the time trends, particularly in the pooled data, are consistent with an implied trend in labor productivity of about 2 percent per year. ${ }^{10}$ The coefficients on the autoregressive term in $I$, although somewhat lower than found in most estimates based on monthly industry data, are not 
Dble 1. Least-Square Butiontes, 1983:2 - 1987:5, Houfactaring Plents
AR(1)
(11)
(6)
$\mathbf{A R}(1)$
(11)
(6)

Pooled (7 plants)

\begin{tabular}{|c|c|c|c|c|c|c|c|c|}
\hline Constant & $\begin{array}{c}4.272 \\
(11.21)\end{array}$ & $\begin{array}{c}6.348 \\
(29.38)\end{array}$ & $\begin{array}{c}4.479 \\
(11.90)\end{array}$ & $\begin{array}{c}4.532 \\
(12.44)\end{array}$ & $\begin{array}{c}6.502 \\
(4.66)\end{array}$ & $\begin{array}{l}5.874 \\
(4.81)\end{array}$ & $\begin{array}{l}5.036 \\
(3.44)\end{array}$ & $\begin{array}{l}5.319 \\
(4.11)\end{array}$ \\
\hline$L_{-1}$ & $\begin{array}{c}.474 \\
(10.15)\end{array}$ & & $\begin{array}{c}.312 \\
(5.94)\end{array}$ & $\begin{array}{c}.269 \\
(5.10)\end{array}$ & $\begin{array}{c}.361 \\
(2.64)\end{array}$ & & $\begin{array}{c}.164 \\
(1.03)\end{array}$ & $\begin{array}{c}.014 \\
(.09)\end{array}$ \\
\hline$t-I_{t}^{*}$ & & $\begin{array}{c}.192 \\
(8.77)\end{array}$ & $\begin{array}{c}.121 \\
(5.03)\end{array}$ & & & $\begin{array}{c}.372 \\
(3.54)\end{array}$ & $\begin{array}{c}.301 \\
(2.39)\end{array}$ & \\
\hline$\Delta Y_{t+3}^{*}$ & & $\begin{array}{c}.042 \\
(4.95)\end{array}$ & $\begin{array}{c}.031 \\
(3.76)\end{array}$ & & & $\begin{array}{c}.202 \\
(1.53)\end{array}$ & $\begin{array}{c}.194 \\
(1.46)\end{array}$ & \\
\hline$Y_{t}$ & & & & $\begin{array}{c}.151 \\
(6.95)\end{array}$ & & & & $\begin{array}{r}.401 \\
(3.71)\end{array}$ \\
\hline Time & & $\begin{array}{r}-.0011 \\
(-.62)\end{array}$ & $\begin{array}{r}-.0011 \\
(-.61)\end{array}$ & $\begin{array}{r}-.0004 \\
(-.25)\end{array}$ & & $\begin{array}{l}-.0010 \\
(-.76)\end{array}$ & $\begin{array}{l}-.0010 \\
(-.81)\end{array}$ & $\begin{array}{c}.0018 \\
(1.42)\end{array}$ \\
\hline $\bar{R}^{2}$ & .220 & .219 & .287 & .310 & .104 & .149 & .168 & .278 \\
\hline $\log x$ & & & -262.62 & -257.11 & & & 34.76 & 37.93 \\
\hline
\end{tabular}

Plant 1

Plant 2

\begin{tabular}{|c|c|c|c|c|c|c|c|c|}
\hline Constant & $\begin{array}{l}8.966 \\
(7.41)\end{array}$ & $\begin{array}{l}8.445 \\
(4.68)\end{array}$ & $\begin{array}{l}8.759 \\
(4.55)\end{array}$ & $\begin{array}{r}-1.602 \\
(-.73)\end{array}$ & $\begin{array}{r}6.320 \\
(5.67)\end{array}$ & $\begin{array}{l}5.305 \\
(3.05)\end{array}$ & $\begin{array}{r}5.708 \\
(3.18)\end{array}$ & $\begin{array}{l}.202 \\
(.12)\end{array}$ \\
\hline$L_{-1}$ & $\begin{array}{l}-.062 \\
(-.43)\end{array}$ & & $\begin{array}{l}-.077 \\
(-.49)\end{array}$ & $\begin{array}{l}-.614 \\
(-3.98)\end{array}$ & $\begin{array}{l}.205 \\
(1.47)\end{array}$ & & $\begin{array}{l}-.136 \\
(-.94)\end{array}$ & $\begin{array}{c}-.340 \\
(-2.15)\end{array}$ \\
\hline$t-I^{*}$ & & $\begin{array}{l}-.007 \\
(-.04)\end{array}$ & $\begin{array}{l}.023 \\
(.14)\end{array}$ & & & $\frac{.344}{(1.84)}$ & $\begin{array}{c}.424 \\
(2.06)\end{array}$ & \\
\hline$\Delta Y_{t+3}^{*}$ & & $\begin{array}{r}-.130 \\
(.88)\end{array}$ & $\begin{array}{l}-.144 \\
(-.95)\end{array}$ & & & $\begin{array}{c}.593 \\
(1.98)\end{array}$ & $\begin{array}{c}.616 \\
(2.05)\end{array}$ & \\
\hline$Y_{t}$ & & & & $\begin{array}{l}1.509 \\
(5.38)\end{array}$ & & & & $\begin{array}{c}1.105 \\
(4.89)\end{array}$ \\
\hline Tine & & $\begin{array}{l}.0027 \\
(.57)\end{array}$ & $\begin{array}{l}.0027 \\
(.56)\end{array}$ & $\begin{array}{l}.0069 \\
(2.25)\end{array}$ & & $\begin{array}{l}=.0236 \\
(-3.62)\end{array}$ & $\begin{array}{r}-.0267 \\
(3.64)\end{array}$ & $\begin{array}{r}-.0048 \\
(-.95)\end{array}$ \\
\hline $\mathrm{R}^{2}$ & -.016 & -.042 & -.059 & .339 & .022 & .273 & .271 & .336 \\
\hline $\log 1$ & & & -20.60 & 13.04 & & & -41.62 & -39.72 \\
\hline
\end{tabular}


male l. $\left(\cos t^{*} d.\right)$

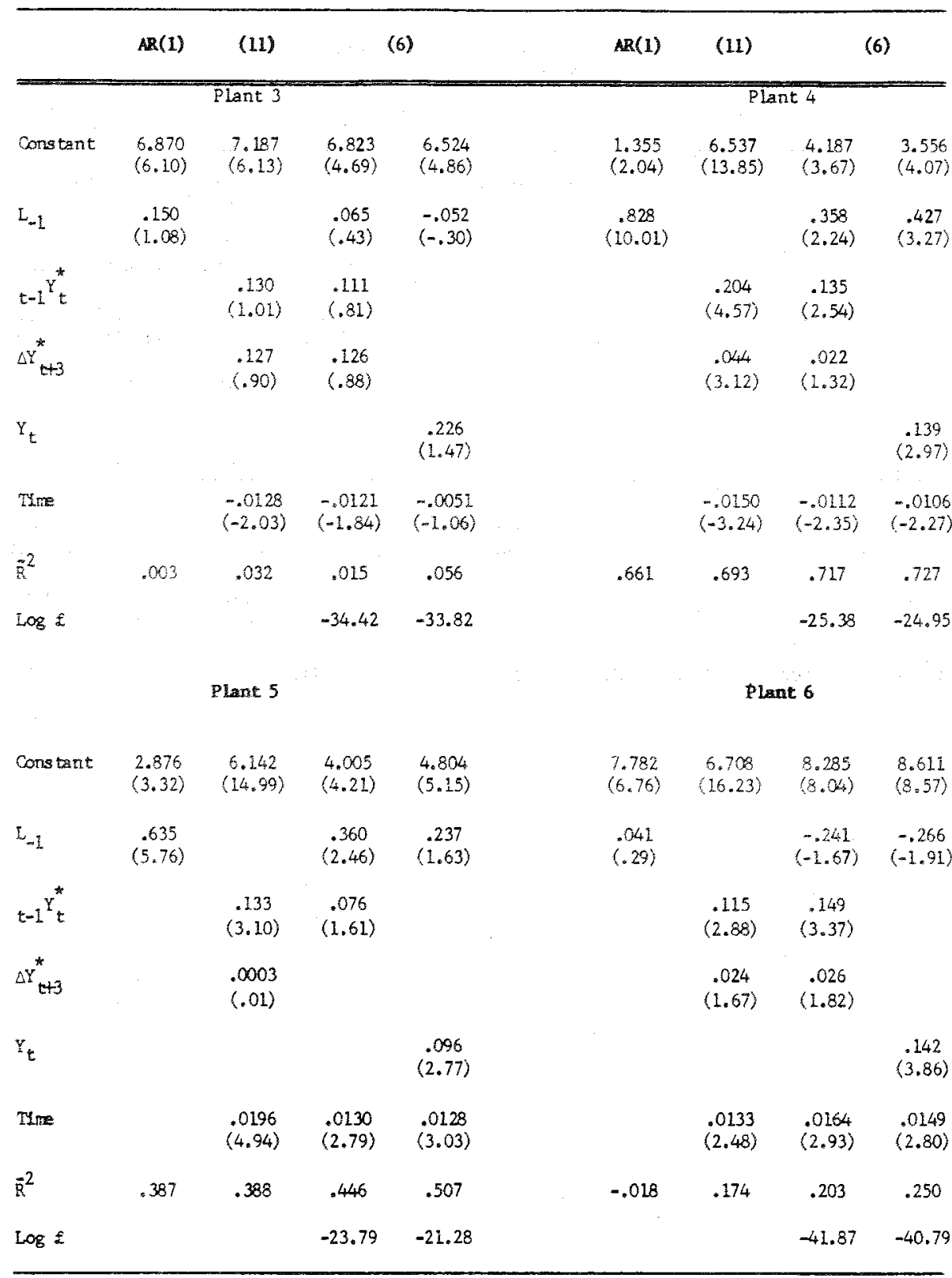

ahere and in Bble 2 there are 52 observations in each case, except in the pooled equations, for which there are 364 observations. t-statistics in parentheses here and in Tables 2-4 umless othe risise noted. 
unreasonable in the pooled data. Moreover, while perfect forecasting (implicit in the fourth column in each tableau) gives a better fit, the forward-looking terms $\Delta \mathrm{Y}_{t+3}^{*}$ do add significantly to the equations.

Table 2 shows the maximum likelihood estimates of the switching mode 1 in (7) for each of six plants, for the pooled data on seven plants, and for those data aggregated. ${ }^{11}$ A comparison of the log-likelihood values of $(6)$ in Table 1 to those for either of the two models in (7) is striking: For all six plants the values of the log-likelihood of model (7) are higher by at least 2 than they are for the equivalent version of model (6) (which has one less estimated parameter). ${ }^{2 Z}$. The clearest comparisons are again on the pooled data. While no nested hypotheses can be tested, $2\left[\log \varepsilon_{1}-\log \varepsilon_{0}\right]=44.5$ and 63.7 for alternatives (10) and (11) estimated over the pooled data. This confirms the impressionistic evidence in Figure 1 that the switching model describes these plant-level data far better than does a model of smooth adjustment. ${ }^{13}$

The estimates of $\mathrm{K}$ are quite large, implying that the firm will change employment levels only in response to very large shocks to expected output. In the pooled data $\hat{\mathrm{K}}=.6$. Consider what an estimate this large means. Unless demand is very slack in these plants, the increases in product demand that occur are met by combinations of greater effort and increased hours per worker. This inference is corroborated by the knowledge that there are large variations in overtime hours in the industry to which these plants belong. With very large changes in product demand, though, firms respond by non-marginal changes in employment. This is the same sequence of responses that is implicit in standard views of how firms adjust. However, the standard view that employment is adjusted marginally is inconsistent with these data. 
The last column of Table 2 presents statistics associated with $\hat{\mathrm{p}}_{\mathrm{t}}$. There is substantial monthly variation in the probability that the firm switches to a new equilibrium. Moreover, for most plants, and in the pooled data, $\hat{p}_{t}$ ranges over most of the interval $(0,1)$. This implies that the model can discriminate fairly well in separating observations onto (7a) and (7b). That the mean of $\hat{\mathrm{p}}_{\mathrm{t}}=.20$, though, shows that it is unlikely at most times that the firm is choosing to change employment.

Recall that these estimates are based on employment levels, and thus, like the theory in Section III, implicitly on costs of net adjustment. We do know, though, that voluntary turnover in the four-digit SIC industry to which these plants belong averaged .8 percent per month in the late 1970 s. ${ }^{14}$ If, as seems likely, this fairly large monthly outflow occurs repeatedly in the same jobs, we may conclude that either that variable hiring costs are not very important to this firm or, more likely, that they are not convex and that the fixed costs of hiring are small. The important nonconvexity in adjustment costs in these plants is in the level of staffing ... in the workplace itse1f rather than in the activities of the personnel office. The sizes of the estimated $k$ indicate that the lumpiness results from economies of scale in maintaining intact an entire work shift or production line.

If one examines Figure 1 it appears that most of the fluctuations in employment represent temporary decreases that are soon restored to the initial employment level. Clearly much of what is occurring in these data is temporary layoffs. Much, though, also reflects permanent changes in the level of staffing, for example, in Plants 2 through 5 at various points during the sample. Even if al1 the discontinuous employment changes represented temporary layoffs, we would still have learned much from examining these employment and output data. Even under this most restrictive (and clearly not entirely correct) interpretation 
the data show that small fluctuations in output demand are not met by changes in employment demand.

This insight is nearly lost when one begins to aggregate the data. The estimates on the aggregated data present an entirely different picture from those on the pooled data or on the individual plants. The $\hat{k}$ are insignificant and very sma1l; and the average values of the $\hat{\mathrm{p}}_{t}$ are much higher than in the pooled data. Also, while (7) describes the data better than does (6), $2\left[\log \mathcal{E}_{1}-\log \mathcal{E}_{0}=7.98\right.$ and 12.32 , far below the differences in the estimates or the pooled data, and below most of the differences in the estimates on the individual plants. Clearly, even at this very low level of aggregation much of the ability to discriminate between models of adjustment costs is lost.

VI. Estimates for Small Industries

To examine problems of model discrimination when further aggregation is made, I obtained published and unpublished data characterizing smal1 (fouxdigit) industries in United States manufacturing. Of the several industries for which the data reflect physical output rather than employee-hours, only four have had the same definition and have sufficiently long continuous series of data on employment and output. These are: SIC 2821, plastics materials and resins; SIC 3221, glass containers; SIC 3632, household refrigerators and freezers; SIC 3633; household laundry equipment.

The monthly data cover all employees. Output is monthly also, with the seasonally unadjusted series used here. ${ }^{15}$ For both series the data cover 1958-1985. Forecasts of $Y$ are constructed exactly as in Section $V$, and the same models are estimated here. With the loss of the observations needed to produce these forecasts and the desire to begin the data set used in estinating (7) with a full year's data, the model is observed over the period 1965-85. Table 3 presents estimates of the same models as did Table 1 . In this 
Thble 2. Egtine tes of (7a) - (70), 1983:2 - 1987:5, ranofacturing Plents

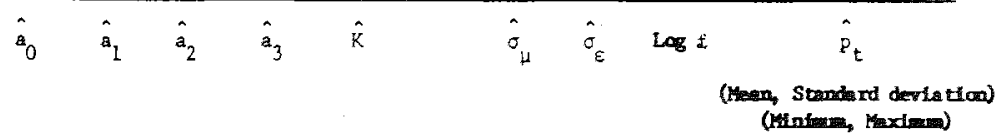

Pooled

\begin{tabular}{|c|c|c|c|c|c|c|c|c|c|c|}
\hline$t-1^{\frac{V^{*}}{*}}, \Delta Y_{t+3}^{*}$ & $\begin{array}{c}6.512 \\
(40.80)\end{array}$ & $\begin{array}{r}.160 \\
(9.24)\end{array}$ & $\begin{array}{l}.046 \\
(4.00)\end{array}$ & $\begin{array}{l}-.0004 \\
(-.38)\end{array}$ & $\begin{array}{l}.584 \\
(8.15)\end{array}$ & .493 & .159 & -230.77 & $\begin{array}{l}(.200 \\
(.045\end{array}$ & $\begin{array}{l}.179) \\
.999)\end{array}$ \\
\hline 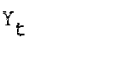 & $\begin{array}{c}5.985 \\
(17.91)\end{array}$ & $\begin{array}{c}.217 \\
(6.19)\end{array}$ & & $\begin{array}{l}-.001 \\
(-.34)\end{array}$ & $\begin{array}{l}.573 \\
(3.52)\end{array}$ & .494 & .621 & -234.86 & $\begin{array}{l}(.465 \\
6.399,\end{array}$ & $\begin{array}{l}.089\rangle \\
.894\rangle\end{array}$ \\
\hline
\end{tabular}

Aggreg ted

\begin{tabular}{|c|c|c|c|c|c|c|c|c|c|c|}
\hline$t-1_{t}^{*}, \Delta Y_{t+3}^{*}$ & $\begin{array}{r}5.132 \\
(3.42)\end{array}$ & $\begin{array}{l}.436 \\
(3.34)\end{array}$ & $(1.71)$ & $\begin{array}{l}-.001 \\
(-.71)\end{array}$ & $\begin{array}{l}.019 \\
(.75)\end{array}$ & .128 & .020 & 38.75 & $\begin{array}{l}(.817 \\
(.342\end{array}$ & $\begin{array}{l}.240) \\
.999)\end{array}$ \\
\hline$t$ & $\begin{array}{l}5.480 \\
(4.56)\end{array}$ & $(3.899)$ & & $\begin{array}{l}.002 \\
(2.09)\end{array}$ & $\begin{array}{l}.031 \\
(.89)\end{array}$ & .119 & .039 & 44.09 & $\begin{array}{l}(.750 \\
(.438\end{array}$ & $\begin{array}{l}.210\rangle \\
.999)\end{array}$ \\
\hline
\end{tabular}

Plant 1

\begin{tabular}{|c|c|c|c|c|c|c|c|c|c|}
\hline$t-1^{H^{*}} t^{3} \Delta Y^{*} t+3$ & $\begin{array}{l}8.521 \\
(2.35)\end{array}$ & $\begin{array}{ll}-.075 & -.723 \\
(-.18) & (-1.92)\end{array}$ & $\begin{array}{l}.018 \\
(.96)\end{array}$ & $\begin{array}{c}.792 \\
(1.80)\end{array}$ & .000 & .781 & -17.85 & $\begin{array}{l}(.395 \\
(.311\end{array}$ & $\begin{array}{l}.115) \\
.814)\end{array}$ \\
\hline$Y_{t}$ & $\begin{array}{c}-3.405 \\
(-17.19)\end{array}$ & $\begin{array}{c}1.170 \\
(57.13)\end{array}$ & $\begin{array}{l}.004 \\
(2.33)\end{array}$ & $\begin{array}{c}.384 \\
(2.09)\end{array}$ & 0 & .225 & 25.20 & $\begin{array}{l}8.236 \\
(.104\end{array}$ & $\begin{array}{l}.232) \\
.999)\end{array}$ \\
\hline
\end{tabular}

Plant 2

\begin{tabular}{|c|c|c|c|c|c|c|c|c|c|c|}
\hline$t-Y_{t}^{*}, \Delta Y_{t+3}^{*}$ & $\begin{array}{l}6.255 \\
(3.88)\end{array}$ & $\begin{array}{l}.246 \\
(1.43)\end{array}$ & $\begin{array}{c}.760 \\
(2.56)\end{array}$ & $\begin{array}{c}-.027 \\
(-5.24)\end{array}$ & $\begin{array}{c}.355 \\
(2.57)\end{array}$ & .512 & .412 & -34.69 & $\begin{array}{l}(.577 \\
6.405\end{array}$ & $\begin{array}{l}.186) \\
.999)\end{array}$ \\
\hline$Y_{t}$ & $\begin{array}{l}.100 \\
(.13)\end{array}$ & $\begin{array}{c}.823 \\
(10.49)\end{array}$ & & $\begin{array}{l}=.001 \\
(-.34)\end{array}$ & $\begin{array}{l}.086 \\
(2.67)\end{array}$ & .555 & .107 & -32.77 & $\begin{array}{l}\{.696 \\
.423\end{array}$ & $\begin{array}{l}.221) \\
.999)\end{array}$ \\
\hline
\end{tabular}

Plant 3

\begin{tabular}{|c|c|c|c|c|c|c|c|c|c|c|}
\hline$t-1 Y_{t}^{*}, \Delta Y_{t+3}^{*}$ & $\begin{array}{l}7.673 \\
(5.92)\end{array}$ & $\begin{array}{l}.086 \\
(.56)\end{array}$ & $\begin{array}{l}.139 \\
(.94)\end{array}$ & $\begin{array}{l}-.016 \\
(-2.21)\end{array}$ & $\begin{array}{l}.113 \\
(.85)\end{array}$ & .468 & .112 & -26.47 & $\begin{array}{l}(.739 \\
(.311\end{array}$ & $\begin{array}{l}.248) \\
.999)\end{array}$ \\
\hline$y_{t}$ & $\begin{array}{c}6.482 \\
(27.54)\end{array}$ & $\begin{array}{l}.188 \\
(7.31)\end{array}$ & & $\begin{array}{l}-.008 \\
(-2.20)\end{array}$ & $\begin{array}{l}.131 \\
(2.34)\end{array}$ & .459 & .145 & -25.69 & $\begin{array}{l}6.724 \\
6.377\end{array}$ & $\begin{array}{l}.227) \\
.999)\end{array}$ \\
\hline
\end{tabular}


Trble 2. (coat'd.)

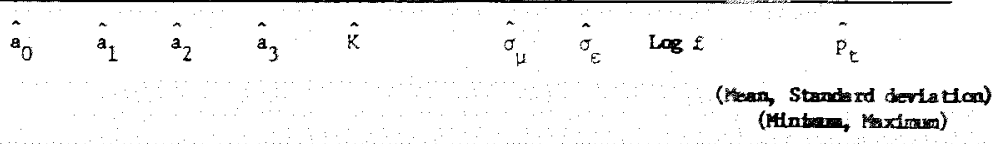

Plant $4^{\circ}$

\begin{tabular}{|c|c|c|c|c|c|c|c|c|c|c|}
\hline$t-1 Y_{t}^{*}, \Delta Y_{t+3}^{*}$ & $\begin{array}{l}4.626 \\
(9.93)\end{array}$ & $\begin{array}{l}.453 \\
(9.65)\end{array}$ & $\begin{array}{l}-.069 \\
(-8.32)\end{array}$ & $\begin{array}{c}-.050 \\
(-16.63)\end{array}$ & $\begin{array}{c}1.492 \\
(12.90)\end{array}$ & .000 & .649 & 27.69 & $\begin{array}{l}(.154 \\
0.021\end{array}$ & $\begin{array}{l}.277) \\
.9957\end{array}$ \\
\hline & $\begin{array}{c}5.005 \\
\langle 14.70\rangle\end{array}$ & $\begin{array}{l}.378 \\
(11.83)\end{array}$ & & $\begin{array}{c}-.029 \\
(-13.41)\end{array}$ & $\begin{array}{c}1.040 \\
(14.54)\end{array}$ & .000 & .474 & 34.54 & $\begin{array}{l}6.173 \\
6.028\end{array}$ & $\begin{array}{l}.224) \\
.968\rangle\end{array}$ \\
\hline
\end{tabular}

Plant 5

\begin{tabular}{|c|c|c|c|c|c|c|c|c|c|c|}
\hline$=-Y^{*} t^{*} \Delta Y_{t+3}^{*}$ & $\begin{array}{r}6.694 \\
\{12.44)\end{array}$ & $\begin{array}{c}.054 \\
(1.02)\end{array}$ & $\begin{array}{l}.0179 \\
(.50)\end{array}$ & $\begin{array}{l}.025 \\
(3.47)\end{array}$ & $\begin{array}{c}.957 \\
(9.44)\end{array}$ & .063 & .968 & -19.69 & $\begin{array}{l}. .363 \\
.323\end{array}$ & $\begin{array}{l}.080) \\
.774\rangle\end{array}$ \\
\hline & $\begin{array}{c}6.270 \\
(19.01)\end{array}$ & $\begin{array}{l}.110 \\
(3.25)\end{array}$ & & $\begin{array}{l}.022 \\
(5.66)\end{array}$ & $\begin{array}{l}.523 \\
(2 * 10)\end{array}$ & 0 & .672 & -16.51 & $\begin{array}{l}.482 \\
.436\end{array}$ & $\begin{array}{l}.094) \\
.954)\end{array}$ \\
\hline
\end{tabular}

Plant 6

\begin{tabular}{|c|c|c|c|c|c|c|c|c|c|c|}
\hline$t-1 Y^{*}, \Delta Y_{t+3}^{\star}$ & $\begin{array}{c}6.671 \\
(39.21)\end{array}$ & $\begin{array}{c}.123 \\
(7.57)\end{array}$ & $\begin{array}{l}.027 \\
(2.91)\end{array}$ & $\begin{array}{l}.012 \\
(3.54)\end{array}$ & $\begin{array}{l}.138 \\
\{2.15\}\end{array}$ & .578 & .137 & -35.44 & $\begin{array}{l}(.681 \\
(.314\end{array}$ & $\begin{array}{l}.2385 \\
.999\end{array}$ \\
\hline & $\begin{array}{c}6.651 \\
(19.90)\end{array}$ & $\begin{array}{l}.127 \\
(5.27)\end{array}$ & & $\begin{array}{l}.014 \\
(2.98)\end{array}$ & $\begin{array}{c}131 \\
(1.78)\end{array}$ & .579 & .128 & -34.49 & $\begin{array}{l}6.591 \\
6.310 .\end{array}$ & $\begin{array}{l}.272) \\
.999\rangle\end{array}$ \\
\hline
\end{tabular}




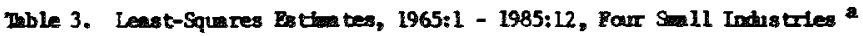

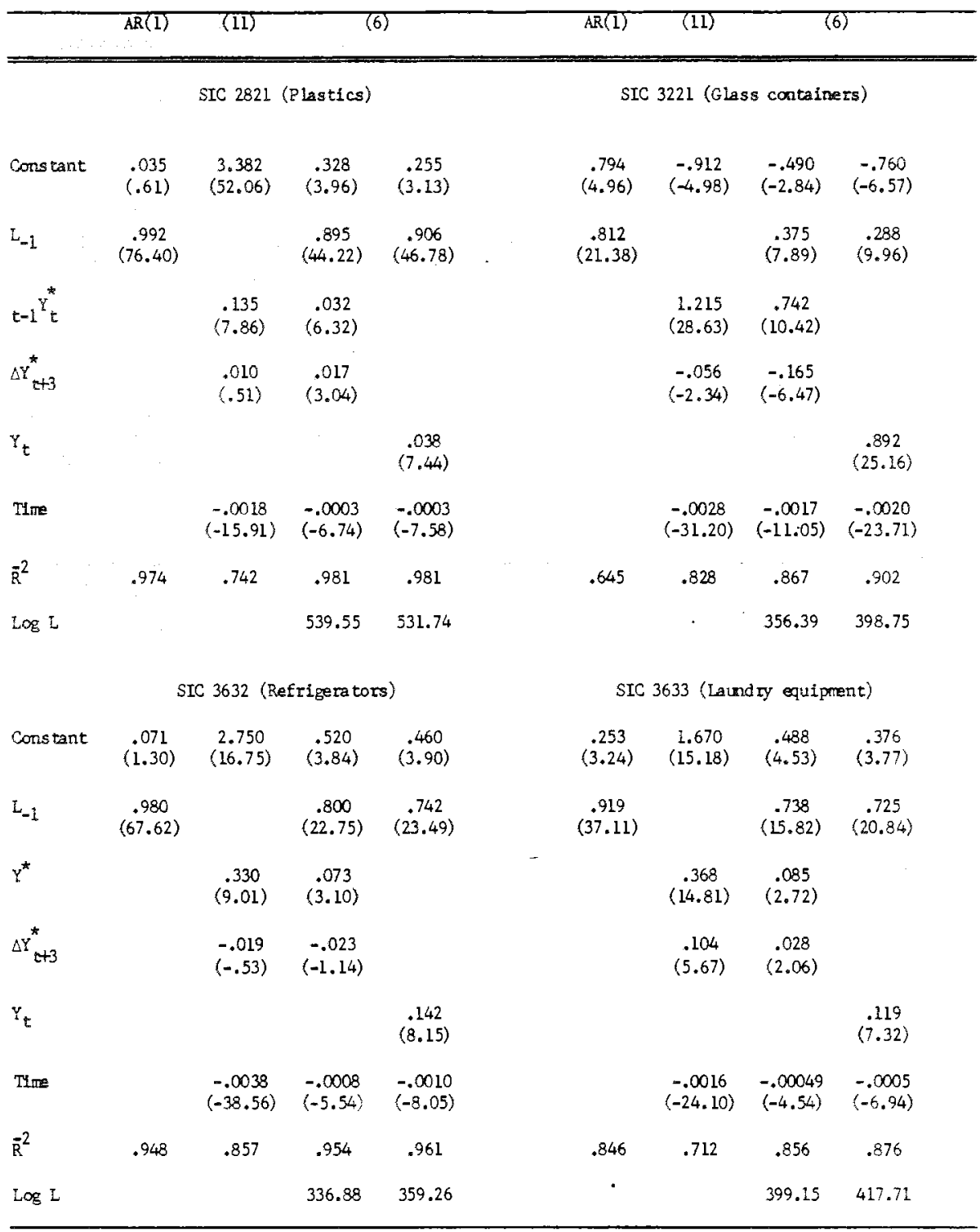

axcept 1973:1 - 1985:12 for SIC 2821, here and Table 4. 
case, though, the estimates cover the four industries over the longer time periods under study. In all industries except SIC 3221 the two ysusions of equation (6) add Iittle explanatory power beyond that provided by a simple AR(1) model. This contrasts sharply to the resuits in Table 1 , where a firstorder autoregression generally explained little of the variation in employment. Moreover, except in SIC 3633 the terrin $\Delta Y_{t+3}^{*}$ is either insignificant or has an unexpected negative sign.

The zesults of astimating (7) under both alternative assumptions about the formation of $L^{*}$ are shown in Table 4 for each of these four suall lndustries Whilo the estimates $\hat{a}_{i}$ make sense, unlige in the previous section the switching model does not uniformly dominate (6): In SIC 2821 the log-1ikelinood is higher in (6) in one case, and essentially the same in the other. The fluctiations in $\left|L_{t-3}-L_{c}\right|$ relative to the $\mathrm{K}$ are such that the average probabilities of switching to a new equilibrium are very 10 , and even the ranges are narrow. This too is a reflection of the inability of the data to discriminate between f first oxder autoregression and the switching model. Even at the level of four-digit SIC industries, testing competing hypotheses about behaviora differences arising from altenative structures of adjustuent costs is confounded by aggregation.

VII. Conclusions, and Implications for Macroeconomlc Ad Justent and J bor-Market Policy

I have demonstrated on data for a particular set of individual plants that the standard model of convex variable adjustment costs is quite inferior to a specification based on adjustment costs that are fixed. For data on small U.S. manufacturing industries, and for data aggregated over a nuber of plants of one manufacturing company, it is more dificult to discriminate between the two models. Clearly, the particular form of adjustment costs that $I$ have chosen is not necessarily a correct description of employment adjustment at 
Thle 4. thes of $(7 a)-(7 b), 1965: 1-1985: 12$, Forr Sen 11 Industries

$\begin{array}{lllllllll}\hat{a}_{0} & \hat{a}_{1} & \hat{a}_{2} & \hat{a}_{3} & \hat{k} & \hat{\sigma}_{j} & \hat{\sigma}_{E} & \log f & \hat{p}_{t}\end{array}$

(Hean, Standard deviatian)

(Hiniment,

SIC 2821

\begin{tabular}{|c|c|c|c|c|c|c|c|c|c|c|}
\hline$t=I^{*} t^{*}, \Delta v_{t+3}^{\star}$ & $\begin{array}{c}3.870 \\
(39.59)\end{array}$ & $\begin{array}{c}.135 \\
(5.94)\end{array}$ & $\begin{array}{c}.070 \\
(3.01)\end{array}$ & $\begin{array}{c}-.002 \\
(-10.54)\end{array}$ & $\begin{array}{l}.104 \\
(4.03)\end{array}$ & .008 & .037 & 535.65 & $\begin{array}{l}(.037 \\
(.005\end{array}$ & $\begin{array}{l}.059) \\
.423)\end{array}$ \\
\hline 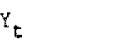 & $\begin{array}{c}3.305 \\
(10.08)\end{array}$ & $\begin{array}{c}.264 \\
(3.48)\end{array}$ & & $\begin{array}{l}-.002 \\
(-5.48)\end{array}$ & $\begin{array}{c}.167 \\
(2.57)\end{array}$ & .008 & .069 & 532.05 & $\begin{array}{l}6.025 \\
(.006\end{array}$ & $\begin{array}{l}.037) \\
.268)\end{array}$ \\
\hline
\end{tabular}

SIC 3221

\begin{tabular}{|c|c|c|c|c|c|c|c|c|c|}
\hline$t-I_{t}^{*}, \Delta Y_{t+3}^{\star}$ & $\begin{array}{l}-3.483 \\
(-49.07)\end{array}$ & $\begin{array}{c}1.795-.125 \\
(96.07)(-2.24)\end{array}$ & $\begin{array}{c}-.004 \\
(-28.87)\end{array}$ & $\begin{array}{c}.375 \\
(9.94)\end{array}$ & .017 & .164 & 613.02 & $\begin{array}{l}(.059 \\
(.022\end{array}$ & $\begin{array}{l}.103) \\
.999)\end{array}$ \\
\hline & $\begin{array}{l}-1.593 \\
(-2.02)\end{array}$ & $\begin{array}{l}1.383 \\
(7.56)\end{array}$ & $\begin{array}{l}-.003 \\
(-8.61)\end{array}$ & $\stackrel{.611}{(3.06)}$ & .007 & .304 & 672.99 & $\begin{array}{l}(.059 \\
(.045\end{array}$ & $\begin{array}{l}.083) \\
.994)\end{array}$ \\
\hline
\end{tabular}

SIC 3632

\begin{tabular}{|c|c|c|c|c|c|c|c|c|c|}
\hline$t-L^{Y^{*}}, \Delta Y_{t+3}^{*}$ & $\begin{array}{l}.441 \\
(.56)\end{array}$ & $\begin{array}{cc}.863 & -.669 \\
(4.88) & (-2.45)\end{array}$ & $\begin{array}{c}-.005 \\
(-11.79)\end{array}$ & $\begin{array}{l}1.926 \\
(2.24)\end{array}$ & .000 & 1.005 & 342.24 & $\begin{array}{l}(.065 \\
(.022\end{array}$ & $\begin{array}{l}.013) \\
.999)\end{array}$ \\
\hline$t$ & $\begin{array}{r}2.166 \\
(3.87)\end{array}$ & $\begin{array}{l}.461 \\
(3.49)\end{array}$ & $\begin{array}{l}-.004 \\
(-9.40)\end{array}$ & $\begin{array}{c}.376 \\
(2.30)\end{array}$ & .050 & .228 & 370.93 & $\begin{array}{r}.149 \\
.099\end{array}$ & $\begin{array}{l}.076 \\
.569)\end{array}$ \\
\hline
\end{tabular}

SIC 3633

\begin{tabular}{|c|c|c|c|c|c|c|c|c|c|c|}
\hline$t=I_{t}^{*}, \Delta Y_{t+3}^{*}$ & $\begin{array}{l}2.245 \\
(8.68)\end{array}$ & $\begin{array}{l}.238 \\
(4.03)\end{array}$ & $\begin{array}{c}.140 \\
(3.20)\end{array}$ & $\begin{array}{c}-.001 \\
(-7.99)\end{array}$ & $\begin{array}{l}.297 \\
(4.93)\end{array}$ & .000 & .224 & 412.55 & $\begin{array}{l}\{.209 \\
6.184\end{array}$ & $\begin{array}{l}.038\} \\
.424)\end{array}$ \\
\hline$Y_{t}$ & $\begin{array}{c}1.879 \\
(225.96)\end{array}$ & $\begin{array}{c}.320 \\
(57.98)\end{array}$ & & $\begin{array}{c}-.001 \\
(-9.73)\end{array}$ & $\begin{array}{c}.237 \\
(55.05)\end{array}$ & .000 & .182 & 435.93 & $\begin{array}{l}(.237 \\
6.190\end{array}$ & $\begin{array}{l}.067) \\
.628)\end{array}$ \\
\hline
\end{tabular}


the micro level. All. I have shown is that, as a sumary of the costs this particular firm faces in the plants it operates, it is better than that embodied in the standard model. Similarly, the lumpy employment adjustnent in these plants may be quite atypical of industry generally; but no one has demonstrated that smooth employment adjustment is typical. Rather, smoothness has heretofore been assumed rather than tested.

This study is the first attempt to compare different models of employment adjustment. It shows that fixed costs characterize adjustment at the plant level. It may be that even at the level of decision-making by firms the standard quadratic cost model is more appropriate. The lumpy adjustment that exists at the plant level may be consistent with the smooth adjustment of shifts of workers across a number of plants operated by a single large firm. Without additional testing on plants in other firms the question cannot be answered. Is it worth doing the additional data collection and research at the appropriate micro level that might cement the abandonment of the standard model? After all, the standard model may describe aggregated data just as well, it leads to simple linear decision rules, and it is much easier to estimate. Aside from a desire for completeness and correctness there are, I believe, many reasons for an affirmative answer to this question.

The first relates to macroeconomic fluctuations in employment and cyclical fluctuations in productivity. Aggregation of individual firms! behavior under the linear equation that is derived from the standard model yields a linear equation characterizing aggregate employment dynamics. This equation implies labor hoarding but no special timing effects. Yet there is a long tradition in macroeconomics (Fair, 1969; Gordon, 1979) of including timing effects in equations "explaining" cyclical productivity change to capture the observation that productivity grows unusually slowly as the economy nears a cyclical peak. These are imposed in an ad hoc fashion; but they are 
consistent with microeconomic structures characterized by fixed costs, so that Iinear aggregation is impossible. Abandoning the standard model requires expanding models of macroeconomic employment adjustment to include information about the distribution of sub-units (in the specification used here, the distribution across (7a) and (7b)). Indeed, for one specific probability density function (the uniform) a mean-preserving spread in demand shocks decreases the aggregate response of employment to those shocks. ${ }^{16}$

Massive and rapid "shake-outs" of employment, such as occurred in 1974-75 and 1982, are also not predicted by the standard model. They are, though, quite consistent with a model with fixed costs in which the response to large shocks is more rapid and disproportionately greater than to smaller shocks.

Slow adjustment has been linked (Nicke11, 1979; Hamermesh, 1986b; Abraham-Houseman, 1987; Burgess, 1988) to the imposition of policies that, for example, make it harder for firms to shed labor through layoffs or plant closings. It is difficult to see how such policies impose an increasing variable cost of adjustment. Unemployment insurance benefits (that are not fully offset by a lower supply price of labor) impose a linear variable cost of adjustment on most employers. Mandatory advance notification of massive layoffs or of plant closings imposes a lump-sum cost that is effective under most proposals only if the drop in employment exceeds some minimum. ${ }^{17}$ other proposed cost-increasing labor-market policies also are hard to analyze in the context of increasing variable adjustrent costs. For example, requiring employers to list all vacancies with the Employment Service, as has been suggested in the United States (e.g., Lawyers' Committee, 1971, p. 99), and as is the norm in some European economies, would impose some fixed costs and Iinear variable costs. Our results and these observations on the likely structure of adjustment costs mean that we cannot readily use previous empirical work to infer their likely impact. Rather, as has been so fruitful. 
in the study of other effects of labor-market policies and social programs, it will be necessary to model their costs carefully and estimate their impacts by applying those models to microeconomic data.

These conclusions should give pause to researchers who worry about complex structures of error terms characterizing dynamic factor adjustnent under the maintained assumption that adjustment is slow because of increasing variable costs. More attention needs to be paid to linking the maximizing behavior that produces factor adjustment to the underlying structure of adjustment costs. That linkage must be made at the micro level, with implications for macro behavior based on determining the correct mectianism for aggregation. The estimates here suggest that the nost profitable approach to studying factor, and particularly employnent adjustment requires obtaining and using microeconoric data to discover what individual firms actually do: 


\section{REFERENCES}

Katharine Abraham and Susan Houseman, "Employment Security and Employment Adjustment," unpublished paper, Brookings Institution, December 1987.

Robert Barro, "A Theory of Monopolistic Price Adjustment," Review of Economic Studies, 39 (1972): 17-26.

Alan Blinder, "Retail Inventory Behavior and Business Fluctuations," Brookings Papers on Economic Activity, (1981): 443-505.

Frank Brechling, Investment and Employment Decisions, Manchester: Manchester University Press, 1975.

Simon Burgess, "Employment Adjustment in UK Manufacturing," Economic Journal, 98 (1988): 81-103.

Robert Eisner and Robert Strotz, "Determinants of Business Investment," in Commission on Money and Credit, Impacts of Monetary Policy, Englewood Cliffs, NJ: Frentice-Hall, 1963.

Ray Fair, The Short-run Demand for Workers and Hours, Amsterdam: North-Holland, 1969.

......., Specification, Estimation and Analysis of Macroeconometric

Models, Cambridge: Harvard University Press, 1984.

Richard Freeman, "Manpower Requirements and Substitution Analysis of Labor Skills," Research in Labor Economics, I (1977): 151-185.

Richard Froyen, Macroeconomics: Theories and Policies, New York: Macmillan, 1983.

John Gennard, "Job Security: Redundancy Arrangements and Practices in Selected OECD Countries," Paris: OECD, 1985.

Stephen Goldfeld and Richard Quandt, "Techniques for Estimating Switching Regressions, "in Idem., Studies in Nonlinear Estimation, Cambridge, MA: Ballinger, 1976.

Robert Gordon, "The 'End-of-Expansion' Phenomenon in Short-Run Productivity Behavior," Brookings Papers on Economic Activity (1979): 447-461.

John Gould, "Adjustment Costs in the Theory of the Finm," Review of Economic Studies, 35 (1968): 47-56.

Daniel Hamermesh, "The Demand for Labor in the Long Run," in Orley Ashenfelter and Richard Layard, Handbook of Labor Economics, Amsterdam: North-Holland, 1986, a. 
Job Security Policies: Theory and Evidence, "National Bureau of Economic Research, Horking Paper No. 2056, Octcber 1986, b.

................. "A Dísaggregative Econometrie Model of Gross Changes in Enployment," Yale Economic Essays, 9 (1969): 107-146.

Robert Hart; The Economics of Non-wage Labour Costs; London: George Allen \& unwin; 1984 .

Charles Holt, Franco Modigiand, Jonn Muth and Herbert Simon, Planning Production, Inventories and Work Force, Engletood Cliffs, NU: erenticeHa11, 1960 .

Lawyers' Comittee for Civil Eughts Under Law, Faling Down on thatob: The United States Employment Service and the Disadvantaged; Wastingtom:

Lamyers" Comittee, 1971 .

M. T. Nadiri and Sherwin Rosen, "Interretated Eactor Demand Furterons," Anerican Econonic Review, 59 (1969): 457-471.

Stephen Nickel1; "An Investigation of the Deteminants of Manufacturitag Employment in the United Kingdom, Revew of Economic Studies, 51 (1984) $529-557$.

.............. "Dynamic Models of Labour Denand, in Oriey shtonenter and pichard Layard, Handbook of Labour Ecomonics, Ansterdan: North-Holland Press, 1986

.............. "Unemployment and the Structure of Labour Costs;" journal of Monetary Eonomics, $11(1979): 187-222$.

Stephen Peck, "Aiternative Investuent Hodels for Fims in the Flectric Utilities Industry," Bell Journal of Economics, 5 (1974) $420-460$.

Shemin Rosen, "Short-rur Employment Variation on Class- Ra lroads in the U.S., 1947-1963," Econometrica, 36 (1968): 511-529.

Michael Rothachild, "On the Cost of adjustment," Quarterly Journal of Economics, 85 (1971): $605-622$

Thomas Sargent, "Estimation of Dyramic Labor Demand Schedules undez Rational. Expectations," Journal of Political Econoray, 86 (1978): 1009-1044.

Matthew Shapiro; "The Dynamic Demand for Capital and Labor," Quarterly Journal of Economics; 101 (1986): $513 \cdot 542$.

Eytan Sheshinski and Yoram Weiss. "Inflation and Costs of Price Adjustment," Review of Economic Studies: 44 (1977): $287-304$.

Robert Tope1, "Inventories, Layoffs, and the Shore-run Demand for Labor," American Economic Review, 72 (1982): $769-787$.

P. K. Trivedi; "Distributed Lags, Aggregation and Compounding: Some 
Econometric Implications," Review of Economic Studies, 52 (1985): 19-35. 


\section{FOOTNCTES}

1.. See Gennard (1985) for a discussion of these policies.

2. There has been some discussion of more general adjustment processes outside the labor area. Rothschild (1971) points out the weakness of the justifications for the quadraticlty of the cost function characterizing the adjustment of the capital stock and shows that costs that are nor-increasing in the size of the adjustment lead to an instantaneous move to a new equilibrium wher a shock occurs. Barro (1972) and Sheshinski-weiss (1977) analyze altemative structures of the cost of adjusting prices. Blinder (1981) examines (S, S) models of inventory adjustment, essentially assuming both fixed and increasing variable costs of adjustment. Aside fron Peck (1974) who analyzed alternative paths of adjustment by forms that inyested in very lumpy. purchases of electricity generation plants; the fer empirical studies based on these models are restricted to aggregated data.

3. In other areas only one of the prongs of this suggested two-pronged approach seens impoxtant.: Most investmett goods and consumer durables purchases are inherentiy lumpy. This means that the najor question of interest to economists studying these should be the nature of the aggregatox of lumpy micro purchases that generates pathe of the observed aggregates.

4. Among the very few avaluble surveys are those conducted by the los Angeles Merchents and Hameracturers Association and by the Employee Managenent Associarion of Raleigh, Ne, These provide dollar costs for selected occupations but do not divide these casts into the categories economists wald use. Nonetheless, it is worth examining their magnitudes. Anong several. broal groups of occupation, hilng and training costs ranged from $\$ 2500$ to $\$ 11,500$, thile separation costs ranged from $\$ 300$ to $\$ 1500$ (hos Angeles

Merchants and Manfacturers Association. Turnovez and Absenteeista Manual, 1980\%. Of course, by itself the relative stze of these costs says rothing about their structure in relation to the size of changes in labor denand.

5. The optimal paths and end points can be derived matats mutandis for an increase in the wage too. Moreover since the wage is just the archetype in this model for a general shock to labor demand, the paths we derive and the inferences about the effects of $b$ and $k$ are general.

6. While factor prices are undoubtedly important, they are not available in my main source of data. Also, there is some evidence that they are less important in affecting the short-run labor-demand fluctuations on which $I$ focus here than are variations in expectations about output (Freenan, 1977).

7. Obviously, decisions about the path of $\mathrm{L}$ are paxt of a larger system in which production, inventories, investment and labot demand are determined by forecasts of all the relevant costs and of sales. Here $I$ examine just one part of this large system and assume that sales expectations can be proxied by expectations about output.

8. Under altemative (11) the number of parameters is one greater for both (6) and (7) (because of the inclusion of $a_{2}$ ). 
9. I present results using only the one-month ahead forecast of output and the expected change three months beyond that. Inclusion of a six-month forecasted change did not add to the quality of the fitted equations for any of the plants. Also, because the estimates of (7) for Plant 7 never converged no matter what starting values or algorithms were chosen, results are presented only for six individual plants. The seventh plant is, though, included in the pooled data and in the estimates based on the aggregate of all plants.

10. We can conduct a brief inquiry into the specification errors in the equations that result from the absence of wage data by examining Figure 1 around the one time during the sample period when a substantial amount of wage information suddenly became available (the one time when a new collective bargaining contract was negotiated). In only one of the seven plants was there a sharp fluctuation (drop) in employsent during that wonth, and in only one of the other plants did employment fluctuate (drop) during the prior month. It is not likely that any of the parameter estinates or our inferences about the nature of paths of employment adjustrent are greatly affected by the absence of wage data for this sample.

11. In all cases the procedure MAXIK in GAUSS is used to find the maxima of the likelihood functions. The particular algorithm chosen is the DavidonFletcher-powell method. The starting values for the parameters were the ols estinates of (6), with $\mathrm{K}$ set equal to 0 and $\sigma_{\epsilon}$ set equal to 1 .

12. One test for serial correlation of the residuals from (7) was performed, ramely estimating the first-order autocorrelation of $\epsilon_{t}$. In none of the plants, nor in the pooled or aggregated data, was the autocorrelation significant.

13. To approximate the general model of Section III a term in $L_{t-1}$ was added to (7b). Its addition did not significanty raise the estimated values of the likelihood functions in either the pooked or the aggregated data, and did so in estimates for oniy one plant.

14. Because of Federal budget cuts, no such turnover data are available for the sample period we use in estimating (6) and (7).

15. The unpublished output data were provided by Kenneth Armitage of the Board of Governors of the Federal Reserve. Unlike in the plant-level data, there is substantial seasonality in the output data for these industries. (About one-third of the variation in output is accounted for by a simple $A R$ (12) mode1.) Despite this, the estimates presented in this section are based on seasonally unadjusted data to maintain comparability with the previous section. The inferences we draw about the inability to discriminate between models of adjustment costs did not differ when the models were reestimated using seasonally adjusted data on output.

16. With fixed adjustment costs, in a simplified model employment change in a plant will be 0 if output change $y\langle k$ or $y\rangle-k$, and be some multiple of $y$ if $|y| \geq k$. Let $y$ be distributed uniformly over the interval $\left[y^{*} \cdot a, y^{*}+a\right]$, with $\operatorname{Pr}\left(y^{m} y^{\prime}\right)=\frac{1}{2 a}$ on this interval and $a>k$. I assume $y^{*}>0$, so average output is rising. Then:

$$
E(y|| y \mid \geq K)=\frac{a y^{*}}{[a-K]} \text {. }
$$

A mean-preserving spread in $y$ involves an increase in a, which implies a 
decrease in if $E(y|| y \mid \geq K)$ a- $K>0$. For a given aggregate change in output, an increase in the dispersion of output change across subunits reduces the average output change anong those units that are varying employment. Since the average change in employment is a multiple of $E(y|y| \geq K)$, it is reduced by the increased dispersion even though $y^{*}$ has not changed.

17. For example, H. 1484, introduced March 9, 1987, required 90 days notice for layoffs or closings involving 50-100 workers; 120 days if 100-500 workers were involved, and 180 days if 500 or more workers were to lose their jobs. 